\title{
Does Short Message Service Increase Adherence to Smoking Cessation Clinic Appointments and Quitting Smoking?
}

\author{
Seda Tural Önür ${ }^{1}$, Mehmet Atilla Uysal ${ }^{1}$, Sinem İliaz ${ }^{2}$, Sibel Yurt ${ }^{1}$, Ayşe Bahadır ${ }^{1}$, Didem Görgün Hattatoğlu ${ }^{1}$, \\ Mediha Gönenç Ortaköylü̈ ${ }^{1}$, Belma Akbaba Bağc1 ${ }^{1}$, Efsun Gonca Uğur Chousein ${ }^{1}$ \\ ${ }^{1}$ Department of Pulmonology, Yedikule Training and Research Hospital for Chest Diseases and Thoracic Surgery, İstanbul, Turkey \\ ${ }^{2}$ Department of Pulmonology, Koç University Hospital, İstanbul, Turkey
}

Background: Using innovative and scientific methods increases the rate of quitting in smokers. Short message service (SMS) is a communication tool widely used and well integrated in many people's daily lives. To increase adherence to appointments in smoking cessation clinics (SCC), it is thought that increased compliance could be achieved by falling outside the traditional methods. SMS has been shown to increase the compliance of patients with SCC appointments.

Aims: In this study, we aimed to evaluate the effect of SMS in the compliance of patients with SCC followup visits and smoking cessation success.

Study Design: Case-control study.

Methods: Our study was a controlled, open, prospective study. We enrolled 436 cases applied to SCC of Yedikule Training and Research Hospital between 01.10.2013-30.06.2014 and agreed to follow-up with SMS. SMS was sent to the patients to remind them of appointments at the SCC and to query their smoking state.

Results: Two hundred-and-eighty seven $(65.8 \%)$ of the patients were male and $149(34.2 \%)$ were female.
The mean age was $45 \pm 12$ years. In this study, 296 $(67.9 \%)$ patients had graduated from primary school. Our patients' smoking state was queried by telephone at the 6-month follow-up and we contacted 348 patients. According to this, $88(25.3 \%)$ patients were not smoking, and $260(74.7 \%)$ patients were smokers. Therefore, the smoking cessation rate was $24 \%$ $(\mathrm{n}=60)$ in patients who did not respond to SMS reminders at all, and $28.6 \%(\mathrm{n}=28)$ in patients answering any SMS at least once

$(p=0.377)$. Smoking cessation rate of the patients invited by SMS but who did not attend any control visits was $19.1 \%$, and it was $34.5 \%$ in patients coming to a control visit at least once. This difference was statistically significant $(\mathrm{p}=0.001)$.

Conclusion: In our study, there was increased success of smoking cessation in patients coming to control visits. We think that this may result from the possibly increased compliance to SCC appointments following reminders by SMS, and that this may also increase smoking cessation success.

Keywords: Cigarette smoking, short message service, smoking cessation, counseling
Smoking is an important factor of morbidity and mortality in Turkey, as it is worldwide. In our country, tobacco is consumed more often than in developed countries. According to data from the Turkish Ministry of Health, $44 \%$ of men and $12 \%$ of women smoke daily (1). Smoking also seems to be a normal and frequent social behavior in our country $(2,3)$.
Despite the high smoking rates in Turkey, half of the people who smoke want to quit smoking, and $45 \%$ of smokers have attempted to quit in the past (1).

By signing the World Health Organization's (WHO) Framework Convention on Tobacco Control, our government's attitude has changed, which caused a decrease in the supply and 
demand of tobacco (4). The right attitude of our government against tobacco and similar noxious substances has attracted the attention of the world $(5,6)$. However, smoking cessation programs still do not reach enough people. To increase quit rates, smoking cessation programs need to be easily accessible by a large number of people. The recent rise of mobile technology, which provides new tools, provides inspiration to investigators in the fight against smoking.

The broad use of the short message service (SMS) creates an attractive new way for medical prevention and intervention $(7,8)$. Mobile phone-based interventions have become an evidence-based and recommended approach for smoking prevention (9-11). A study revealed that $84 \%$ of adults in Turkey had mobile phones, $64 \%$ of which used SMS (12). Compared with the Internet, a mobile-based approach could be superior with regards to access and usefulness because this method gives reactive messages that are more efficient than proactive ones to its users (13). Investigations showed a strong effect of motivational interviews in smoking cessation $(14,15)$. SMSbased systems are more scalable for community health and more efficient in cost analysis because of the widespread use of mobile phones (16). These results support the efficiency of SMS-based smoking cessation programs in western countries $(17,18)$. In addition, recent studies conducted in our country showed that SMS-based smoking cessation programs seemed to be acceptable and feasible $(19,20)$.

Our hypothesis was that increasing motivational compliance of patients with smoking cessation clinic (SCC) appointments using SMS might increase smoking cessation rates.

\section{MATERIALS AND METHODS}

\section{Patients}

Our study was performed in our hospital's SCC with patients who were referred between October 2013 and June 2014. Patients who were aged more than 18 years, wanted to quit smoking, and had mobile phones and the ability to reply to incoming SMS in the follow-up were enrolled in the study. The participants signed a consent form to participate in the trial. Patients who did not approve to being followed-up using SMS were excluded from the study and received routine smoking cessation counseling without SMS.

\section{Study design}

Our study was a controlled, open label, prospective study. Patients were sent SMS reminders for appointments and the smoking cessation date. The patients were also asked if they would attend follow-up visits or they had quit smoking. In the follow-up examinations during smoking cessation counsel- ing, exhaled carbon monoxide (CO) measurements (Bedfont Scientific LTD; Maidstone, England, 2008) were performed. After at least 6 months of follow-up, the patients were called by phone and asked about their smoking situation. Attendance of at least one follow-up visit, responding to SMS messages, and quitting smoking within 6 months were the endpoints of the study. If the patients attended at least one follow-up visit, then they were accepted as an attendee. Similarly, if the patients responded to at least one SMS, then they were accepted as an SMS responder. We evaluated these parameters and the relationships between them. After the first appointment, a reminder message for the next appointment was sent. The content of this SMS was "Our patient who wants to quit smoking, you have an appointment on ../../.. at xxx hospital smoking cessation outpatient clinic. Please inform us if you are coming or not by replying with 1 if yes or 0 if no." Afterwards, the patients were evaluated in the SCC and their demographic data recorded. The pharmacotherapy and behavioral therapy were planned according to the patients' individual requirements, and the smoking cessation date was decided.

On the smoking cessation day, we sent an SMS to remind the participants of the smoking cessation day and the next appointment saying "Dear ...., we remind you that today is your smoking cessation day, we congratulate you for doing an excellent thing for yourself and those around you. You have an appointment on ....... at xxx hospital smoking cessation policlinic. Please inform us if you are coming or not by replying 1 if yes or 0 if no." After that, further SMS messages containing "Dear ...., please reply with 1 if you are still smoking or 0 if not" were sent; smoking status was questioned monthly. In total, we sent at least four SMS for each participant during the 6-month follow-up period. SMS were sent to the patients to remind each appointment date and the smoking cessation date. The number of SMS increased if the patients attended the follow-up visits. If they did not, we stopped sending the SMS. After at least 6 months of follow-up, the patients were called and asked about their smoking status.

\section{SMS invitation system}

The text message provider designed a computer interface. A secretary added the patient's phone number to the system, and the number was then sent to the text message provider via the Internet. When the provider received the number, the software was triggered at the appropriate time. The algorithm was similar to that used by Huang et al. (21). The cost of the SMS system was $\$ 700$ (USD), and all costs were covered by the authors. The SMS system gave data on dates and the number of SMS messages sent, a report on the SMS reaching the participants, and the patients' responses. All data were summarized and interpreted by the authors. 


\section{Smoking cessation methods}

Our hospital is a tertiary care center that serves patients with pulmonary diseases. In our SCC, smokers are evaluated by pulmonologists who are specialized in smoking cessation. Smoking cessation counseling in our hospital is based on universal and national smoking cessation guidelines $(22,23)$. The pharmacotherapy options available in Turkey are nicotine gums and patches, bupropion, and varenicline tablets. Pharmacotherapy was used according to the history of patients and their Fagerström Test for Nicotine Dependence (FTND) scores (24). Comorbid conditions of the smokers also affected the choice of drug. Most of the smokers in the present study were at least prescribed nicotine gum to deal with abstinence, and a group of patients were given only motivational/behavioral therapy instead of pharmacotherapy.

\section{Statistical analysis}

Statistical analysis was performed using Statistical Package for Social Sciences (SPSS) version 22 (IBM Corp.; Armonk, NY, USA) software. Descriptive Values were given as mean and standard deviation. Categorical variables were expressed as the number of cases and the percentage value. Kolmogorov-Smirnov and Shapiro-Wilk tests were used to determine whether continuous variables were appropriate to a normal distribution. In the comparison of groups, Student's t-test and Mann-Whitney $U$ test were used according to the normality of distribution of the variables. The comparison of categorical variables was performed using Chi-square and Fisher's exact tests. Statistical significance was set as $p<0.05$.

\section{RESULTS}

A total of 436 patients agreed to SMS follow-up, and these were included in our study (a flow chart of the study is given in Figure 1). At their first examination, demographic data and habits were recorded (Table 1). Two hundred and eightyseven $(65.8 \%)$ of the patients were men, and 149 (34.2\%) were women. The mean age was $45 \pm 12$ years. In this study, $296(67.9 \%)$ patients had graduated from primary school. One hundred and nineteen (27.2\%) patients responded with at least one SMS, and 317 (72.8\%) patients did not respond at all. The SMS responders and non-responders had similar age, sex, marital status, education and working situation, and also similar FTND scores (all p values $>0.05$ ) (Table 1). Our patients' smoking status was investigated by telephone in the $6^{\text {th }}$ month of follow-up; we were able to contact 348 patients (details provided in Table 1). According to the phone call follow-up, 88 (25.3\%) patients were not smoking, and $260(74.7 \%)$ had continued to smoke. We could not reach 88 patients $(20.2 \%)$ by phone. Of those 348 patients with 6-month follow-up data; 98 were SMS responders (at least one response) and 250 were non-responders. In the evaluation of patients with 6-month follow-up results, the smoking cessation rate was $24 \%(n=60)$ in patients who did not respond to SMS reminders at all, and was $28.6 \%(\mathrm{n}=28)$ in patients who answered any SMS at least once. There was no statistically significant difference between quitting rates of SMS responders and non-responders $(\mathrm{p}=0.377)$. Comparison between SMS responders and non-responders is given in Table 2.

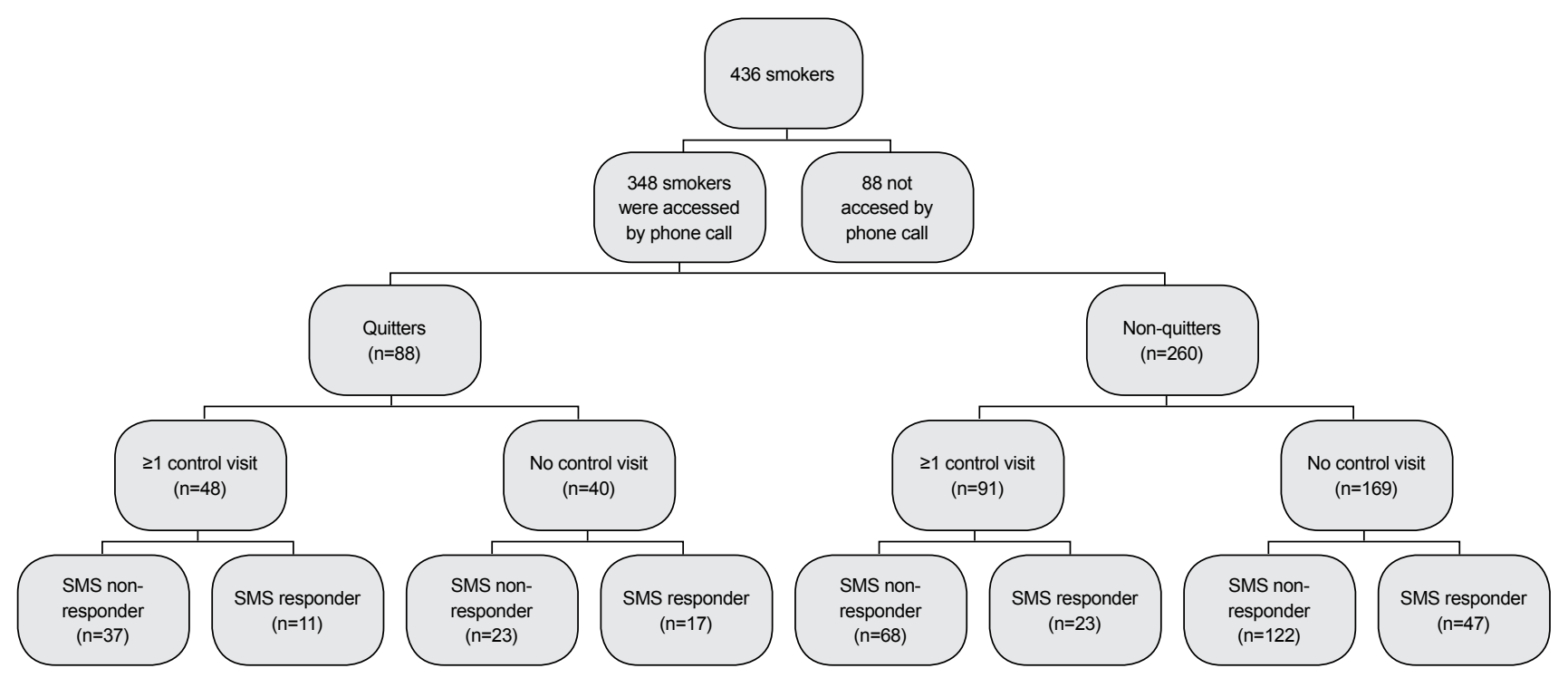

FIG. 1. Flowchart of smokers in the study 
TABLE 1. Demographic data of the patients

\begin{tabular}{|c|c|c|c|c|}
\hline & \multirow[b]{2}{*}{$\begin{array}{l}\text { All patients } \\
(\mathrm{n}=436)\end{array}$} & \multicolumn{3}{|c|}{ Accessed patients by phone call $(\mathrm{n}=348)$} \\
\hline & & $\begin{array}{l}\text { SMS responders } \\
\quad(\mathrm{n}=98)\end{array}$ & $\begin{array}{l}\text { SMS non- responders } \\
\qquad(\mathrm{n}=250)\end{array}$ & Significance \\
\hline Age (years, mean \pm SD) & $45 \pm 12$ & $44 \pm 12$ & $45 \pm 11$ & $\mathrm{p}=0.43$ \\
\hline \multicolumn{5}{|l|}{$\operatorname{Sex~n~(\% )~}$} \\
\hline Male & $287(65.8 \%)$ & $59(60.2 \%)$ & $175(70 \%)$ & $\mathrm{p}=0.08$ \\
\hline \multicolumn{5}{|l|}{ Marrital Status n (\%) } \\
\hline Single & $76(17.4 \%)$ & $23(23.5 \%)$ & $40(16 \%)$ & $\mathrm{p}=0.23$ \\
\hline Married & $326(74.8 \%)$ & $67(68.4 \%)$ & $192(76.8 \%)$ & $\mathrm{p}=0.23$ \\
\hline Other & $34(7.8 \%)$ & $8(8.2 \%)$ & $18(7.2 \%)$ & $\mathrm{p}=0.23$ \\
\hline \multicolumn{5}{|l|}{ Having children n (\%) } \\
\hline Yes & $349(80.1 \%)$ & $74(77.1 \%)$ & $202(81.1 \%)$ & $\mathrm{p}=0.23$ \\
\hline \multicolumn{5}{|l|}{ Educational Status n (\%) } \\
\hline$\leq 8$ years of education & $296(67.9 \%)$ & $60(61.2 \%)$ & $166(66.4 \%)$ & $\mathrm{p}=0.63$ \\
\hline \multicolumn{5}{|l|}{ Working Status n (\%) } \\
\hline Not working & $110(25.23 \%)$ & $25(25.5 \%)$ & $60(24 \%)$ & $\mathrm{p}=0.76$ \\
\hline Irregularly paid worker & $38(8.72 \%)$ & $7(7.1 \%)$ & $23(9.2 \%)$ & $\mathrm{p}=0.76$ \\
\hline Regularly paid worker & $147(33.72 \%)$ & $36(36.7 \%)$ & $83(33.2 \%)$ & $\mathrm{p}=0.76$ \\
\hline Self-employed & $39(8.94 \%)$ & $7(7.1 \%)$ & $28(11.2 \%)$ & $\mathrm{p}=0.76$ \\
\hline Retired & $102(23.39 \%)$ & $23(23.5 \%)$ & $56(22.4 \%)$ & $\mathrm{p}=0.76$ \\
\hline FTND score $($ mean \pm SD) & $6 \pm 2.5$ & $6 \pm 2.5$ & $5.9 \pm 2.6$ & $\mathrm{p}=0.67$ \\
\hline
\end{tabular}

SMS: short message service; FTND: Fagerström test for nicotine dependence

TABLE 2. Smoking status and control visit attendance according to SMS response status in accessed patients via phone call

\begin{tabular}{lccc}
\multicolumn{4}{c}{ Accessed patients by phone call $(\mathrm{n}=348)$} \\
\cline { 2 - 4 } & $\begin{array}{c}\text { SMS } \\
\text { responders } \\
(\mathrm{n}=98)\end{array}$ & $\begin{array}{c}\text { SMS } \\
\text { non responders } \\
(\mathrm{n}=250)\end{array}$ & \\
& $\mathrm{n}(\%)$ & $\mathrm{n}(\%)$ & Significance \\
\hline Quitters & $28(28.6)$ & $60(24.0)$ & $\mathrm{p}=0.37$ \\
Non quitters & $70(71.4)$ & $190(76.0)$ & \\
At least one control visit $(\mathrm{n} / \%)$ & $34(34.7)$ & $105(42.0)$ & $\mathrm{p}=0.21$ \\
No control visit $(\mathrm{n} / \%)$ & $64(65.3)$ & $145(58.0)$ & \\
\hline
\end{tabular}

SMS: short message service

Data of attendance, at least one follow-up visit and responding to SMS reminders are given in Table 2 and Figure 1. Thirty-four (34.7\%) patients among the 98 SMS responders attended at least one follow-up appointment. There was no significant difference between patients who responded to SMS reminders and those who attended follow-up clin-
TABLE 3. Smoking status about clinic attendance in patients contacted via phone call

\begin{tabular}{lccc}
\hline & \multicolumn{3}{c}{ Accessed patients via phone call $(\mathrm{n}=348)$} \\
\cline { 2 - 4 } & $\begin{array}{c}\text { At least } \\
\text { one control } \\
\text { visit }(\mathrm{n}=139)\end{array}$ & $\begin{array}{c}\text { No control } \\
\text { visit } \\
(\mathrm{n}=209)\end{array}$ & \\
& $\mathrm{n}(\%)$ & $\mathrm{n}(\%)$ & Significance \\
\hline Quitters & $48(34.5)$ & $40(19.1)$ & $\mathrm{p}<0.01$ \\
Non quitters & $91(65.5)$ & $169(80.9)$ & $\mathrm{p}<0.01$ \\
\hline SMS: short message service & & & \\
\hline
\end{tabular}

ics $(\mathrm{p}=0.210)$. The smoking cessation rate of patients who were invited by SMS but failed to attend any follow-up visit was $19.1 \%$ (40 patients in 209 ), and was $34.5 \%$ (48 patients in 139) in patients who attended follow-up clinics at least once. This difference was statistically significant $(\mathrm{p}=0.001)$ (Table 3). Forty-five (37.8\%) of the 119 SMS responders (in total of 436 patients) sent a message indicating that they would attend their first appointment; however, 32 of them $(71.1 \%)$ did not attend. 
TABLE 4. The distribution of smoking cessation pharmacotherapy

\begin{tabular}{lcccc}
\hline & & \multicolumn{3}{c}{ Accessed patients by phone call $(\mathrm{n}=348)$} \\
\cline { 3 - 5 } & $\begin{array}{c}\text { All patients } \\
(\mathrm{n}=436)\end{array}$ & $\begin{array}{c}\text { SMS responders } \\
(\mathrm{n}=98)\end{array}$ & $\begin{array}{c}\text { SMS non- responders } \\
(\mathrm{n}=250)\end{array}$ & \multicolumn{1}{c}{ Significance } \\
\hline No pharmacotherapy & $83 / 19 \%$ & $18 / 18.3 \%$ & $52 / 20.8 \%$ & 0.61 \\
NRT & $138 / 31.6 \%$ & $25 / 25.5 \%$ & $59 / 23.6 \%$ & 0.70 \\
Bupropion & $119 / 27.3 \%$ & $24 / 24.5 \%$ & $69 / 27.6 \%$ & 0.55 \\
Varenicline & $157 / 36 \%$ & $35 / 35.7 \%$ & $89 / 35.6 \%$ & 0.98 \\
\hline
\end{tabular}

NRT: nicotine replacement therapy (gum and/or patch)

*The pharmacotherapy options given here may have been used in combination.

Treatment decisions were made according to FTND total scores, comorbidities that could increase adverse effects, and patients' choice. We have presented data based on quitting success, appointment attendance, and responsiveness to SMS for each drug used. We provided pharmacotherapy unless there was a risk of severe adverse effects or contraindications for all patients' FTND $\geq 5$.

The distribution of pharmacotherapy choices in this study is given in Table 4. Most of the participants $(79.9 \%)$ were prescribed nicotine replacement therapy (NRT), bupropion, or varenicline. However, $20.1 \%(n=70)$ of the participants received only motivational/behavioral therapy for smoking cessation. When we compared any pharmacologic treatment option with the rest of the group for smoking cessation, attendance at follow-up visits, and responsiveness to SMS, there was no statistically significant difference with regards to treatment (for NRT vs. rest of the group $\mathrm{p}=0.61, \mathrm{p}=0.36, \mathrm{p}=0.70$; for bupropion vs. rest of the group $p=0.07, p=0.83, p=0.55$; for varenicline vs. rest of the group $\mathrm{p}=0.67, \mathrm{p}=0.21, \mathrm{p}=0.98$, respectively).

\section{DISCUSSION}

Short message service is widely used and an excellent integrated communication tool in most people's daily life. Our study's aim was to increase adaptation to SCC appointments by using an unconventional method. Our study showed that SMS-based intervention might affect smoking cessation success by increasing compliance with SCC appointments.

Technology is changing rapidly. This opportunity may be developed and used to fight against smoking using evidencebased interventions. The advances in technology may facilitate reaching a larger number of people. Even though important progress has been made in substance abuse prevention and treatment methods, tobacco remains an obstacle in community health problems. The cooperation of patients in outpatient clinic follow-up creates a significant problem in dealing with smoking addiction. A recent meta-analysis of 13 studies using SMS in smoking cessation counseling suggested that SMS based interventions generally increased quit rates when compared with no intervention (25). Another study investigating SMS based intervention for smoking cessation in young adults aged 18-25 years showed an increase in smoking cessation in the short-term (4 weeks after cessation), but the data on long-term results was not sustained and it was inconclusive (26). The study of Naughton et al. (27) showed similar quit rates with SMS intervention for the short-term (4 and 8 weeks after quit date), but the 6th month long-term results favored SMS intervention. For those who want to quit smoking, researchers are investigating how often it is necessary to send an SMS through a system and which kind of system should be used. Balmford and Borland (28) reported a study on different methods of SMS messaging during smoking cessation. One method based on reporting changes in quit status and the other one gave emergency help. Those methods were both interactive, automated text messaging advice programs. The study showed that the average number of messages per day was $4-8$, and median use of messaging system was 27 days. The patients also reported their smoking status changes, but the study showed that relapses were less likely to be reported than continuing quit status. Emergency help was used in only $27 \%$ of cases, and using emergency help was not related with shortterm results of smoking cessation. As a result, the authors concluded that the success of using SMS messaging systems was variable among smokers.

In Ybarra et al.'s (19) study, which was conducted in Turkey, 75 smokers who planned to quit smoking in the following 30 days were included in a 6-week SMS program. The participants were contacted on the day after their quit day, and on their sixth day after quitting and were asked whether they were currently smoking. Subsequent content was then based on whether the participant had maintained their non-smoking status. For each of the two days, if participants reported smoking a puff of a cigarette or more in the previous 24 hours, they were sent relapse messages. If participants reported no 
smoking, they received messages that focused on strategies to remain as a non-smoked. If participants were smoking on both days 2 and 7 after the quit day, they were routed to messages that encouraged them to try quitting again in the future. The participation in the program was high, with $51 \%$, and smoking cessation success was observed in $13 \%$. This study showed that SMS programs were usable and acceptable methods in countries with a high rate of smokers, like Turkey (19). In our study, rather than sending SMS messages according to smoking status, patients were asked if they had remained nonsmokers. In our study population, the SMS response rate was $27 \%$. The reasons for this were low level of education, and low initial motivation or maybe not seriously thinking about quitting smoking. While using SMS systems, calling SMS non-responders by phone and asking if they were still willing to continue follow-up and why they had not responded to SMS messages may increase the success of the system. Even though our SMS reply rate was lower, our responders' smoking cessation ratio was $28 \%$, which was higher than in the study of Ybarra et al. (19).

In the randomized controlled study by Mason et al. (29), 72 adolescents were sent 30 SMS messages and their 6-month follow-up results were evaluated. They found statistically significant differences between the experimental and control group regarding the number of days in which cigarettes were smoked in the past 30 days, readiness to quit, close friends who smoke daily, and the refusal of cigarettes from a friend. The strongest effect of SMS system was reducing daily smoked cigarettes. Also, the SMS group had reduced intentions of smoking in the future. This study suggested that using technology and smart phones in smoking cessation clinics helped to reach the adolescent population (29). Similarly, Naughton and his colleagues showed that an SMS system could be used in primary prevention in community health (27).

In our study, the quit rate of the patient group who did not attend any follow-up appointments despite having been invited using an SMS reminder was statistically significantly lower than the quit rate of the patient group who attended followup appointments at least once $(\mathrm{p}=0.001)$. Even though there was no difference between responders and non-responders according to demographic data and smoking cessation rates, SMS messages might increase the rate of patients who attend follow-up clinics, which has been attributed to smoking cessation success. We think that the use of an SMS system in SCC is worthy of investigation in large-scale population studies. Text messaging intervention is efficient and has widespread use. It could provide an attractive, affordable model to increase smoking abstinence rates among adults, including those with lower educational level, independent of their motivation to quit.
There are some limitations to our study. Smoking status was given by the patients themselves; no biochemical verification methods were used. Secondly, we had a low number of patients enrolled in our study compared with previous similar studies, and the SMS response rate was also not as high as previously reported. This may have been related to the low educational status of our SCC population. This study did not clearly show that SMS invitations increased 'attendance to control appointments' because many factors could have affected this outcome. For example, greater compliance may be due to participants' better motivation. In addition, we do not have the data on quitters' and ongoing smokers' mean/median number of control visits to compare. We analyzed these two groups as coming to at least one control visit or attending none. Furthermore, a higher successful quit rate may be because of lower dependence or better motivation, rather than attendance at follow-up appointments. However, there is no widely-used validated questionnaire or brief assessment tool to measure motivation to quit smoking for our country $(30,31)$.

In conclusion, we found that there was a higher rate of success with smoking cessation among patients who attended follow-up appointments. We believe that SMS invitation may increase outpatient clinic compliance and smoking cessation success because this rate was higher than in patients who did not attend follow-up appointments.

\section{Ethics Committee Approval: N/A.}

Informed Consent: Written and verbal consent was obtained from the patients who particiapted in this study.

Peer-review: Externally peer-reviewed.

Author contributions: Concept - M.A.U.; Design - M.A.U, S.T.Ö., S.İ.; Supervision - M.A.U., M.G.O., A.B., S.Y.; Resource M.A.U., S.T.Ö., S.İ., S.Y., A.B., M.G.O., D.G.H., B.A.B., E.G.U.C.; Materials - D.G.H., B.A.B., E.G.U.C.; Data Collection and/or Processing - M.A.U., S.T.Ö., S.İ., S.Y., A.B., M.G.O., D.G.H., B.A.B., E.G.U.C.; Analysis and/or Interpretation - M.A.U., S.T.Ö., S.İ.; Literature Search - M.A.U., S.T.Ö., S.İ.; Writing - M.A.U., S.T.Ö., S.İ.; Critical Reviews - S.Y., A.B., M.G.O., D.G.H., B.A.B., E.G.U.C .

Acknowledgements: The authors would like to thank Mr. Chapman for English language editing.

Conflict of Interest: No conflict of interest was declared by the authors.

Financial Disclosure: The cost of the SMS system was $\$ 700$, and all costs were covered by the authors. There is no other financial supporter. 


\section{REFERENCES}

1. Ministry of Health Turkey Global Adult Tobacco Survey: Turkey report. 2010.

2. Ghouri N, Atcha M, Sheikh A. Influence of Islam on smoking among Muslims. BMJ 2006;332:291-4. [CrossRef]

3. Yuksel H, Corbett KK. Mixed messages: a qualitative study of the meanings and context of high school students' tobacco use in Turkey. Health Promot Int 2005;20:360-6. [CrossRef]

4. WHO Framework Convention on Tobacco Control. Status of payments of voluntary assessed contributions (VAC) as of 31 March 2015.

5. World Health Organization. Turkey marks progress in fight against noncommunicable diseases. 2012.

6. Devi S. Turkey wins plaudits for tobacco control. Lancet 2012;379:1935. [CrossRef]

7. Wei J, Hollin I, Kachnowski S. A review of the use of mobile phone text messaging in clinical and healthy behavior interventions. J Telemed Telecare 2011;17:41-8. [CrossRef]

8. Cole-Lewis H, Kershaw T. Text messaging as a tool for behavior change in disease prevention and management. Epidemiol Rev 2010;32:56-69. [CrossRef]

9. Youth Risk Behavior Surveillance-United States, 2011. MMWR 2012;61:1-162.

10. Cunningham JA, Kypri K, McCambridge J. The use of emerging technologies in alcohol treatment. Alcohol Res Health 2011;33:320-6.

11. Newman MG, Szkodny LE, Llera SJ, Przeworski A. A review of technology-assisted self-help and minimal contact therapies for anxiety and depression: is human contact necessary for therapeutic efficacy? Clin Psychol Rev 2011;31:89-103. [CrossRef]

12. Pew Global Attitudes Project. Global digital communication: texting, social networking popular worldwide, 2011.

13. Sherman SE, Takahashi N, Kalra P, Gifford E, Finney JW, Canfield $\mathrm{J}$, et al. Care coordination to increase referrals to smoking cessation telephone counseling: a demonstration project. Am J Manag Care 2008;14:141-8.

14. Colby SM, Monti PM, O'Leary Tevyaw T, Barnett NP, Spirito A, Rohsenow DJ, et al. Brief motivational intervention for adolescent smokers in medical settings. Addict Behav 2005;30:86574. [CrossRef]

15. Peterson AV Jr, Kealey KA, Mann SL, Marek PM, Ludman EJ, Liu J, et al. Group-randomized trial of a proactive, personalized telephone counseling intervention for adolescent smoking cessation. J Natl Cancer Inst 2009;101:1378-92. [CrossRef]

16. Ybarra ML, Eaton WW. Internet-based mental health interventions. Ment Health Serv Res 2005;7:75-87. [CrossRef]

17. Whittaker R, Borland R, Bullen C, Lin RB, McRobbie H, Rodgers A. Mobile phone-based interventions for smoking cessation. Cochrane Database Syst Rev 2009:CD006611. [CrossRef]

18. Free C, Knight R, Robertson S, Whittaker R, Edwards P, Zhou $\mathrm{W}$, et al. Smoking cessation support delivered via mobile phone text messaging (txt2stop): a single-blind, randomized trial. Lancet 2011;378:49-55. [CrossRef]

19. Ybarra ML, Bagci Bosi AT, Bilir N, Holtrop JS, Korchmaros $\mathrm{J}$, Emri S. Interest in technology-based and traditional smoking cessation programs among adult smokers in Ankara, Turkey. Tob Induc Dis 2011;9:10. [CrossRef]

20. Ybarra ML, Holtrop JS, Bagci Bosi AT, Bilir N, Korchmaros JD, Salih Emri AK. Feasibility and acceptability of a text messaging-based smoking cessation program in Ankara, Turkey. $J$ Health Commun 2013;18:960-73. [CrossRef]

21. Huang F, Liu SC, Shih SM, Tao YH, Wu JY, Jeng SY, et al. Reducing the anxiety of surgical patient's families access short message service. AMIA Annu Symp Proc 2006:957.

22. European Smoking Cessation Guidelines: The authoritative guide to a comprehensive understanding of the implications and implementation of treatments and strategies to treat tobacco dependence. 1st edition. October 2012.

23. Türk Toraks Derneği, Tütün kontrolü çalışma grubu. Sigara b1rakma tanı ve tedavi uzlaşı raporu, 2014. 1.Bask1, Ankara, 2014.

24. Uysal MA, Kadakal F, Karşidağ C, Bayram NG, Uysal O, Yilmaz V. Fagerstrom test for nicotine dependence: reliability in a Turkish sample and factor analysis. Tuberk Toraks 2004;52:11521.

25. Spohr SA, Nandy R, Gandhiraj D, Vemulapalli A, Anne S, Walters ST. Efficacy of SMS text message interventions for smoking cessation: A meta-analysis. J Subst Abuse Treat 2015;56:1-10. [CrossRef]

26. Ybarra ML, Holtrop JS, Prescott TL, Rahbar MH, Strong D. Pilot RCT results of stop my smoking USA: a text messaging-based smoking cessation program for young adults. Nicotine Tob Res 2013;15:1388-99. [CrossRef]

27. Naughton F, Jamison J, Boase S, Sloan M, Gilbert H, Prevost AT, et al. Randomized controlled trial to assess the short-term effectiveness of tailored web- and text-based facilitation of smoking cessation in primary care (iQuit in practice). Addiction 2014;109:1184-93. [CrossRef]

28. Balmford J, Borland R. How do smokers use a smoking cessation text messaging intervention? Nicotine Tob Res 2014;16:158692. [CrossRef]

29. Mason MJ, Campbell L, Way T, Keyser-Marcus L, Benotsch E, Mennis J, et al. Development and Outcomes of a Text Messaging Tobacco Cessation Intervention with Urban Adolescents. Subst Abus 2015;36:500-6. [CrossRef]

30. Kotz D, Brown J, West R. Predictive validity of the Motivation To Stop Scale (MTSS): a single-item measure of motivation to stop smoking. Drug Alcohol Depend 2013;128:15-9. [CrossRef]

31. Borland R, Yong HH, Balmford J, Cooper J, Cummings KM, O'Connor RJ, et al. Motivational factors predict quit attempts but not maintenance of smoking cessation: findings from the International Tobacco Control four country Project. Nicotine Tob Res 2010;12 Suppl:S4-11. [CrossRef] 